\title{
GIANT-CELL TUMOURS AND ANEURYSMAL BONE CYSTS OF THE SPINE
}

\author{
With Special Reference to the Problems Related to the \\ Removal of a Vertebral Body
}

\author{
H. Verbiest, Utrecht, Netherlands
}

From the Neurosurgical Department, State University of Utrecht

Giant-cell tumours of bone were probably first described by Cooper and Travers in 1818. Nélaton (1860) designated them " tumeurs à myeloplaxes." The name giant-cell tumour was introduced by Bloodgood (1919). Stewart (1922) regarded the giant cells as an integral part of the growth and believed that they were related to the osteoclasts of normal bone; he proposed the term osteoclast sarcoma, from which the name osteoclastoma developed. In many older publications the diagnosis of giant-cell tumour of bone has been applied with insufficient precision, to include various other bone lesions in which multinucleated giant cells were found. In $1940 \mathrm{Jaffe}$, Lichtenstein and Portis attempted to define what should properly be regarded as a genuine giant-cell tumour. In their opinion it is a distinctive neoplasm arising from the non-osteogenic supporting connective tissue of the marrow, which can be readily identified on the basis of its cytological details. Special tumour types previously classified as giant-cell tumours were recognised as separate entities, such as benign chondroblastoma of bone, non-osteogenic fibroma of bone and aneurysmal bone cyst. Jaffe and Lichtenstein assumed that the occurrence of a giant-cell tumour of bone in the vertebral column was rare and believed that many of the vertebral giant-cell tumours described in the literature were in reality aneurysmal bone cysts. The following clinical, radiological, gross pathological and histological characteristics have been advanced to distinguish between the two conditions.

Age-Aneurysmal bone cysts occur chiefly in the young. Nine out of ten patients treated in the Mayo Clinics (McCarty, Dahlin, Doyle, Lipscomb and Pugh 1961) were from ten to fifteen years old, and Hess (1960) estimated that 75 per cent of patients were under twenty. Giant-cell tumours of bone tend to occur in older persons. Of Schajowicz's (1961) eighty-five patients fifty-eight were aged between twenty and forty and only nine were aged between fifteen and twenty. In Williams, Dahlin and Ghormley's (1954) series of 101 patients ninety-one were over twenty. In Mnaymneh, Dudley and Mnaymneh's (1964) material the incidence in the second decade was relatively high-eleven out of forty patients. These statistics are of little value in individual diagnosis because aneurysmal bone cysts may occur in persons of over twenty and giant-cell tumours of bone have been reported in patients of under twentyeven, in one of Jaffe's patients, at the age of ten.

Localisation-In the long bones the position of an aneurysmal bone cyst is eccentric and it is typically seen in the metaphysial area, not extending into the epiphysial end of the bone, whereas giant-cell tumours of bone involve the epiphysial end and often invade the adjacent metaphysis. In the vertebral column there is no such difference in localisation. According to modern views vertebral giant-cell tumours are rare, and are most frequently found in the sacrum.

Behaviour-An aneurysmal bone cyst is considered a benign lesion but recurrence and even extension of the lesion after incomplete removal have been reported (McCarty et al. 1961, Donaldson 1962).

Giant-cell tumours of bone show a great tendency to recurrence after incomplete removal, and about 10 per cent show a malignant evolution. McCarty and his colleagues stated that only two aneurysmal bone cysts reported had undergone malignant changes and that both 
had been subjected to radiotherapy. It should be borne in mind that a high proportion of giant-cell tumours of bone develop malignant features after irradiation.

Radiographic features-In a typical case of aneurysmal bone cyst there is rarefaction of the bone and ballooning of the bony cortex giving a blow-out appearance of part of the contour of the affected bone area. Intracystic trabeculation may give rise to the so-called soap-bubble effect. Giant-cell tumours produce rarefaction of the bone, the overlying cortex being expanded and thinned. The radiological appearance of an aneurysmal bone cyst may be atypical, as for instance when the usual thin shell of bone fails (McCarty et al. 1961; Paillas, Serratrice and Legré 1963).

Gross pathology-Usually an aneurysmal bone cyst presents itself as an expanded lesion surrounded by a thin layer of subperiosteal bone. After removal of the bony shell blood wells up, and inside there is a honeycombed mass of spaces filled with fluid blood. The tissue is usually soft but may feel gritty when osteoid tissue is present, and is reddish or yellow. In two of Donaldson's (1962) cases the cysts were empty except for serous yellow fluid. Paillas et al. stated that the capsule is always resistant, not allowing invasion of surrounding tissue by the tumour. There may be exceptions, however, as was reported by Donaldson (1962): in one of his patients the tumour extended through a vertebral lamina and out into the paravertebral region. McCarty et al. (1961) described unusual features in two cases: in one the tumour surrounded the spinal canal; in the other the tumour was not sharply demarcated from the adjacent normal bone but looked like a malignant lesion.

Giant-cell tumours of bone are usually surrounded by an expanded thin cortex of subperiosteal new bone (Jaffe 1958) but penetration of the cortex and invasion of neighbouring soft tissue by tumour occurs, especially in advanced cases or in cases of recurrence after operation. The colour of the tumour may vary from grey to light or dark red. Areas of haemorrhage or necrosis are often seen and cystic cavities may be present. The consistency of the tumour tissue varies from friable to firm. In one of Mnaymneh, Dudley and Mnaymneh's (1964) cases the tumour was found to be a cystic lesion with sero-sanguineous contents, looking like an aneurysmal bone cyst.

Microscopic pathology-The aneurysmal bone cyst is occupied by cavernous vascular spaces which may or may not be lined by endothelial cells, and the other features of the walls of blood vessels are absent. These spaces are separated by thin or thick slightly fibrous septa, containing strands of osteoid tissue, variable amounts of fibrous tissue, multinucleated giant cells, spindle-shaped stromal-cell nuclei and macrophages laden with haemosiderin. The giant cells tend to be rather small and contain fewer nuclei than those of giant-cell tumours of bone. The blood in the spaces is not clotted. Occasionally non-cystic zones may occupy one-half of the lesion.

In giant-cell tumours of bone the cavernous vascular spaces are absent. In the zones of active growth there is little collagenous stroma and the giant cells lie among stromal cells, the latter being round, oval or fusiform, containing larger nuclei with little chromatin. The giant cells contain usually more than fifteen to twenty nuclei. Parts of the tumour may show haemorrhage, necrosis or cicatricial fibrosis. Areas composed of spindle cells of a fibroblastic type with abundant intercellular collagenous substance and occasionally groups of lipidbearing foam cells reflect, according to Jaffe, a pattern of spontaneous regression and healing of the tumour. Its predominance indicates a favourable prognosis. Frequently the tumour shows many newly formed blood vessels, with walls composed only of endothelial cells. There may also be vascular channels lined by an endothelial layer or by the tumour cells themselves, thus explaining abundant haemorrhage, both recent and old. Phagocytosis of blood pigment is frequently found. Trabeculae of osteoid may be present (Lichtenstein 1959, Schajowicz 1961).

It may thus be concluded that age, the site of localisation in the individual vertebra, the radiographic and gross pathological appearances are no infallible criteria for the differential diagnosis between aneurysmal bone cyst and giant-cell tumour in the spine, so that judgement 
has to rely principally on microscopical examination. Many authors think that the histological features of these conditions are so distinctive that there is no difficulty in diagnosis, but others are more guarded. Paillas et al. (1963), for instance, stated that there was a close similarity in structure, which accounted for the diagnostic errors.

Today vertebral giant-cell tumours are considered extremely rare. This is clearly expressed by the comment of McCarty et al. (1961) that " any lesion in this location that looks as if it may be a giant-cell tumour is almost always an aneurysmal bone cyst or some other giant-cell variant."

Recently an intermediate point of view was expressed by Bucy (1962). After reviewing his spinal cases with the pathologist Humphreys, he stated that although the spinal giant-cell tumours in his material were different from those of the long bones, it would be misleading to apply the term " aneurysmal bone cyst " because the lesion could not be described as cystic, while the term itself gave no indication of their neoplastic or progressive character.

Personal experience in seven cases of spinal affection collected over the past twenty-three years supports Bucy's view. All the pathological specimens except that of Case 7, which was lost when our clinic was partially destroyed in an air raid during the second world war, were re-examined by various pathologists; in addition, the specimens of Cases 2, 4, 5 and 6 were submitted to the Netherlands Council for Bone Tumours.

In the cases of giant-cell tumour an attempt has been made to grade the tumours, although there is a difference of opinion between authors like Jaffe (1958) and Lichtenstein (1959), who stressed the importance of grading, and others such as Johnson and Dahlin (1959), who found no correlation between the initial microscopic aspect of the tumour and the prognosis.

Most authors agree that whenever radical surgical removal of a giant-cell tumour of bone is possible, it is undoubtedly the method of choice. In cases of involvement of vertebral bodies this form of treatment presents particular difficulties in repair and stabilisation of the spinal column. For this reason the following cases have been divided into those limited to the vertebral arches and those with involvement of vertebral bodies.

\section{CASE REPORTS}

GIANT-CELL TUMOURS OF BONE IN THE VERTEBRAL ARCH

Case 1-A man of twenty-one began to have trouble with walking in November 1954. By the time he was admitted in February 1955 he had a tetraplegia with loss of sensation below the third thoracic level. At that time radiographs showed that the left articular processes, pedicles and arches of the fourth and fifth cervical vertebrae had been destroyed (Fig. 1). Myelography showed that there was a block at the level of the fifth cervical vertebra.

At operation in February 1955 it was found that the left side of the laminae of the fourth and fifth cervical vertebrae had been eroded by the tumour, which extended on the left of the dural sac at the level of the third and fourth cervical vertebrae and occupied the left intervertebral foramina between the fourth and fifth and the fifth and sixth cervical vertebrae. All the tumour mass was removed. Its colour varied from light red to grey or yellowish. There were no cavities inside it. Histological examination showed a typical giant-cell tumour with the appearances of spontaneous regression and healing described by Jaffe (Figs. 2 and 3).

Fig. 1

Case 1-Radiograph showing destruction of left articular processes, pedicles and arches of fourth and fifth cervical vertebrae.

VOL. 47 B, NO. 4, NOVEMBER 1965

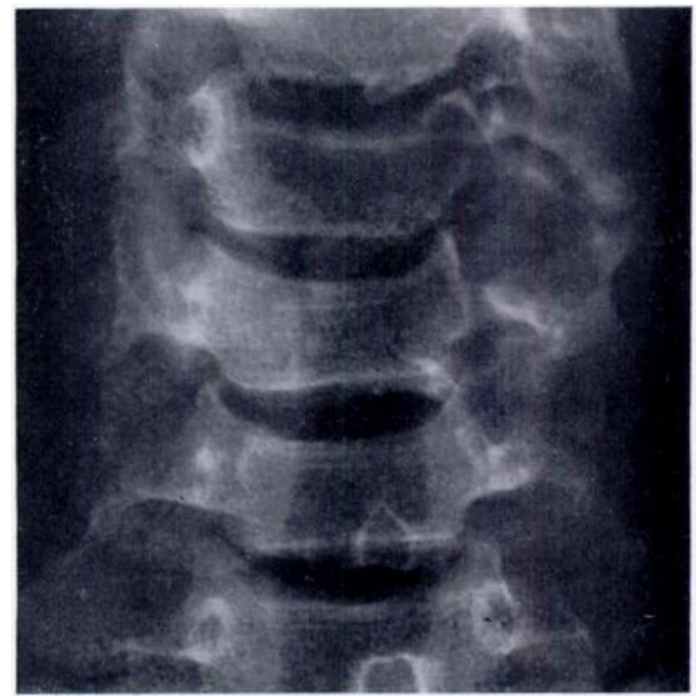

Fig. 1 


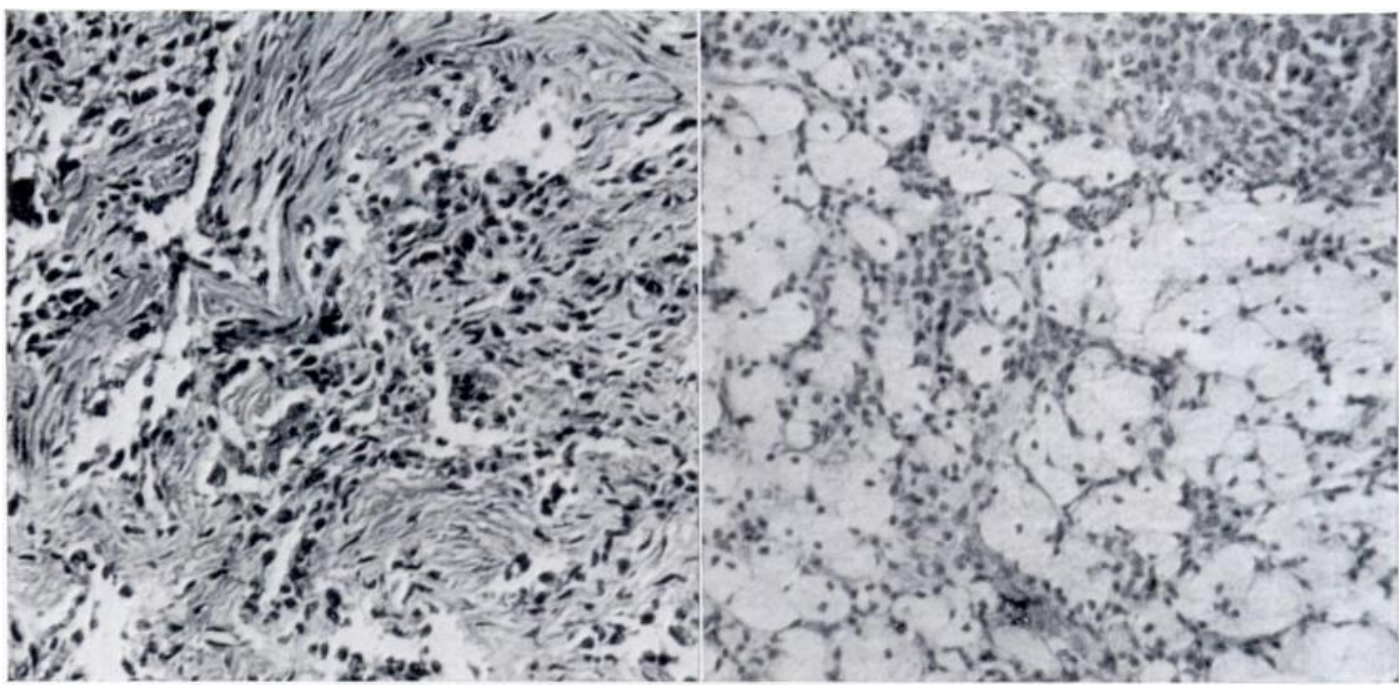

Fig. 2

Fig. 3

Case 1. Figures 2 and 3-Histological appearances. Figure 2-Few giant cells. Spindling and whorling of stromal cells. Thin-walled vascular spaces. Presence of intercellular collagenous material. $(\times 160$. $)$ Figure $3-$ Part of the tumour showing lipid-bearing cells. $(\times 160$.)

One year later the patient had almost completely recovered sensibility and motor power. Seen ten years after operation he was found to be in good health, to be working as a farmer and to have no complaints. There was no evidence of recurrence.

Case 2-A girl of sixteen suffered for one and a half years from pains in the nape of the neck and in the shoulders. In March 1958 she lost the power in both arms and two months later both lower limbs

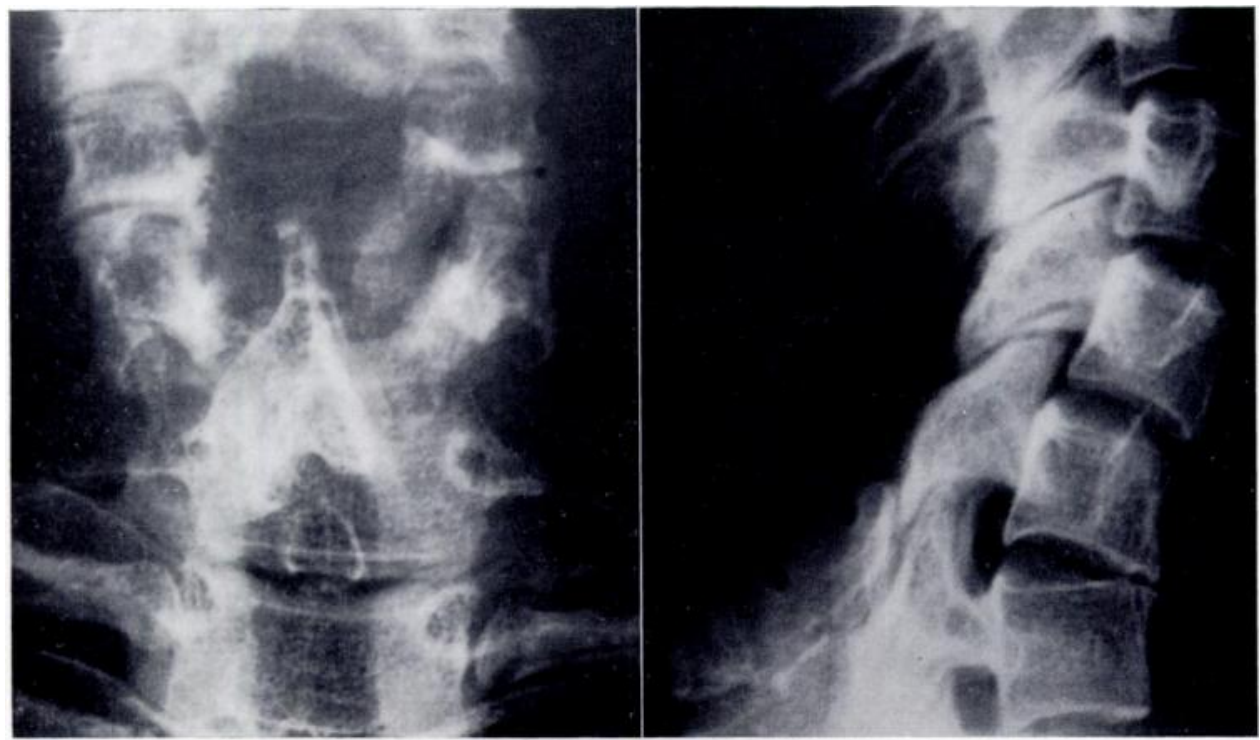

Fig. 4

Case 2-Antero-posterior and lateral radiographs showing considerable destruction of lamina and spinous process of the fourth cervical vertebra and complete destruction of fifth cervical lamina and spinous process. The eroded lamina and spinous process of the sixth cervical vertebra are displaced downward.

were paralysed too. She was admitted in June 1958 with tetraplegia: there was loss of sensation below the fourth thoracic level and there was disturbance of bladder function. Radiographs showed anterior angulation of the cervical spine with considerable destruction of the laminae and spinous process 
of the fourth cervical vertebra, complete destruction of the laminae and spinous process of the fifth cervical vertebra and erosion of the laminae and spinous process of the sixth cervical vertebra. The latter were detached from their vertebra and were apparently displaced downward (Fig. 4).

At operation in June 1958 a tumour was found infiltrating the posterior muscles of the neck. There was a peridural extension at the level of the fifth, sixth and seventh cervical vertebrae. The tumour extended into the intervertebral foramina. All visible tumour mass was removed. Histological examination showed the typical appearances of a giant-cell tumour of Grade I (Fig. 5).

The patient recovered rapidly from the neurological disturbances and in 1964 , nearly six years after operation, was in good health and showed no signs of recurrence.



FIG. 5

Case 2-Histological appearances. Whorling and spindling of the stromal cells. Few giant cells. Thin-walled vessels. $(\times 160$.

Case 3-A man of forty-one began in November 1947 to have pain in the left buttock radiating to the back of the left lower limb. He was admitted to hospital in February 1948 and at that time there was diminution of the left patellar reflex, absence of the ankle reflexes and anaesthesia in the first to the third sacral dermatomes. Pain could be produced by pressure in the sacral area. Radiographs did not show any obvious abnormality in the sacrum. Lumbar puncture was done and the protein level in the cerebro-spinal fluid was found to be 106 milligrams per 100 millilitres. Myelography showed a complete block at the lower margin of the fifth lumbar vertebra.

At operation in March 1948 erosion of the posterior wall of the sacral canal caused by a reddish-grey tumour mass was found at the level of the first to the third sacral segments. Most of the tumour, which was highly vascular, was removed by curettage. Histological examination showed appearances of a giant-cell tumour in some parts of the growth, whereas other parts appeared frankly malignant with a sarcomatous type of stroma (Figs. 6 and 7). The tumour was classified as Grade III.

The patient received radiotherapy after operation, but died at home five months later.

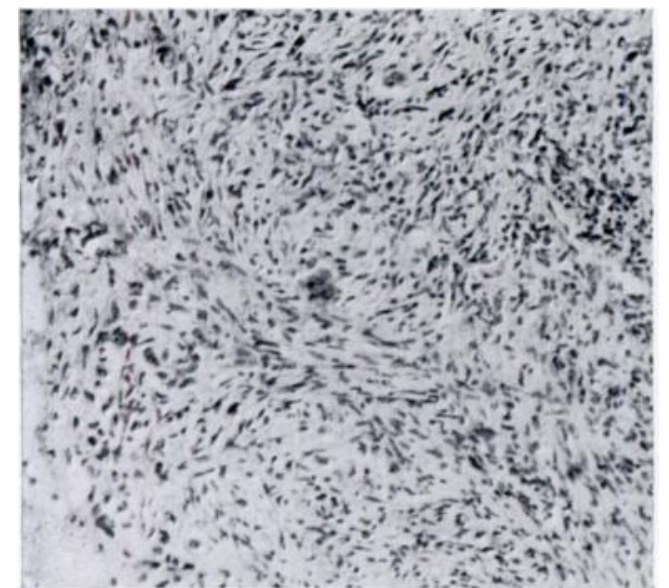

Fig. 6

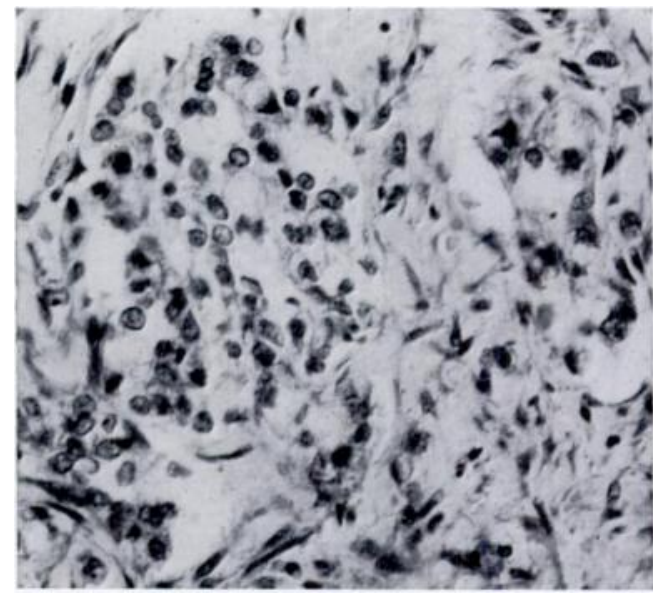

Fig. 7

Case 3-Histological appearances. Figure 6-Part of the tumour shows whorling and spindling of stromal cells and only few giant cells. $(\times 80$. $)$ Figure 7-Aggressive portion of the tumour. L.oss of polarity of stromal cells. Hyperchromatic and anaplastic nuclei. $(\times 200$.)

VOL. 47 B, NO. 4, NOVEMBER 1965 


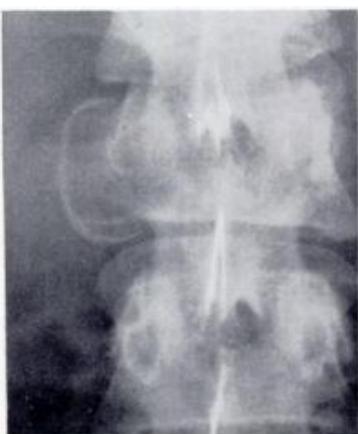

FIG. 8

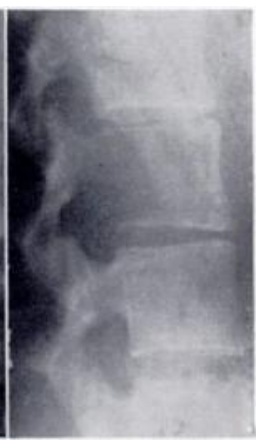

FIG. 9
FIGS. 8 AND 9

Case 4. Figure 8-Antero-posterior view, showing expanded portion of second lumbar vertebra with thin

shell of cortex. Figure 9-Lateral view, showing rarefaction in posterior portion of the body of the second lumbar vertebra.

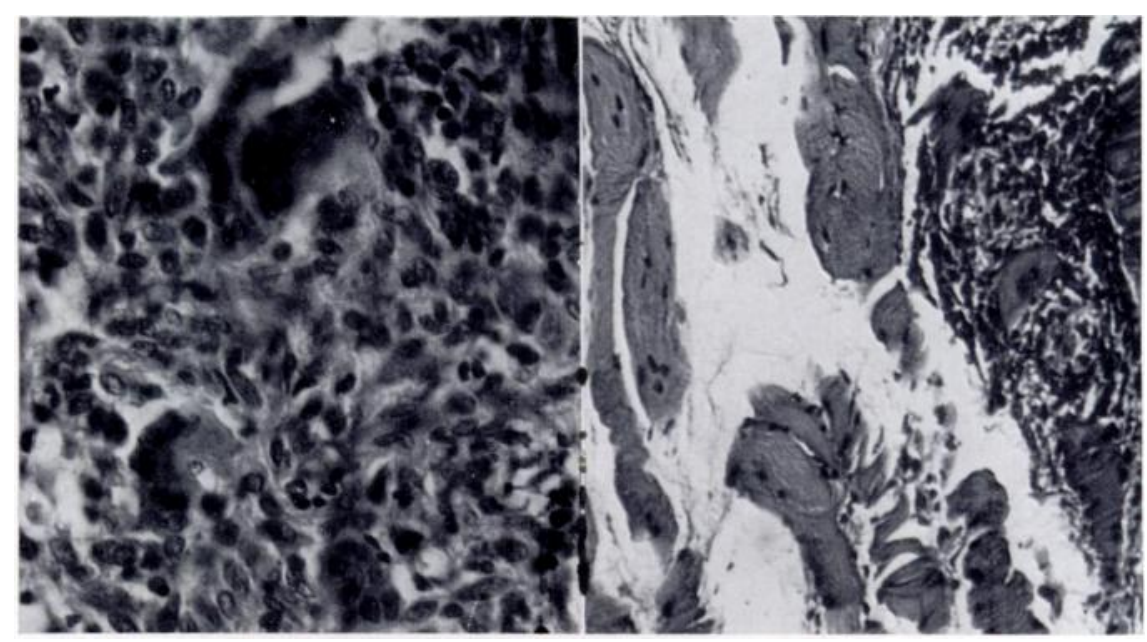

Fig. 10

Fig. 11

Case 4. Figure 10-Abundant and closely compacted plump or ovoid stromal cells, many of their nuclei being hyperchromatic. $(\times 240$. $)$ Figure 11 -Invasion of psoas muscle by tumour. $(\times 75$.)

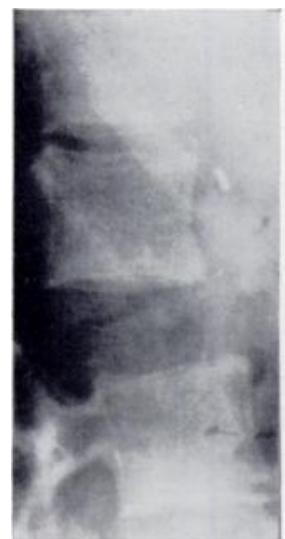

FIG. 12

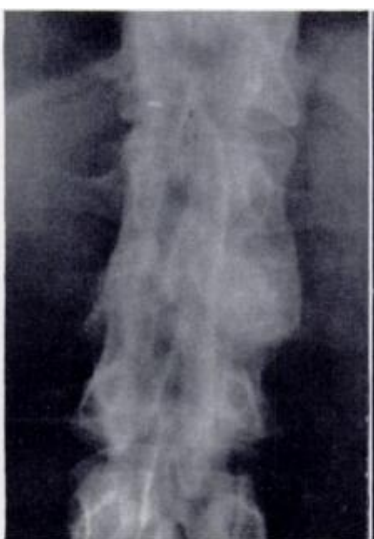

FIG. 13

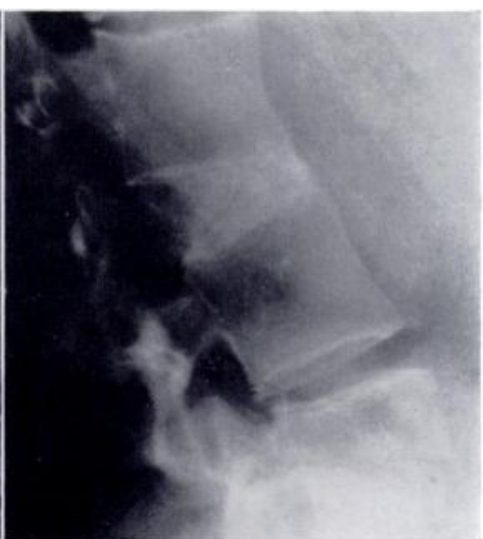

FiG. 14

Case 4. Figure 12-The gap after removal of the second lumbar vertebral body. Figures 13 and 14-Six years after bone grafting. The gap between the first and third lumbar vertebral bodies has been bridged by bone and there is only slight kyphosis. 
GIANT-CELL TUMOURS INVOLVING VERTEBRAL BODIES

Case 4-A girl of twenty-three had had severe pain in the lumbar region for two years. Radiographs showed destructive changes in the second lumbar vertebra, and she was admitted to the local hospital for radiotherapy. During this treatment she awoke one morning with a complete paraplegia and loss of sensibility in both lower limbs. The slightest movement produced very severe pain in the lumbar region radiating into the lower limbs. Radiotherapy was stopped: at the time she had received a tumour dose of 1,800 röntgens.

She was admitted in August 1958 with paralysis of the feet and of the toes. The power of the other parts of the lower limbs could not be assessed because attempts to do so caused so much pain in the back. There was, however, diminution of sensibility below the second lumbar level. Radiographs showed that the right lateral part of the second vertebral body had a "blow-out" appearance. The expanded and transradiant right part of this vertebral body was surrounded by a thin shell of cortex. The lateral view showed rarefaction of the posterior and middle part of the affected vertebral body (Figs. 8 and 9).

Operation was done in August 1958. A right antero-lateral extraperitoneal approach was made. There was a brownish discoloration of the origin of the psoas muscle at the level of the first to the third lumbar vertebrae, and at the second lumbar vertebral level there was a bulge caused by an underlying reddish-brown tumour mass which had invaded the muscle. Most of the vertebral body was occupied by tumour which centrally had a greyish colour. The tumour was freely removed, this removal involving complete extirpation of the vertebral body, the adjoining intervertebral discs and much of the psoas muscle. There were no cysts or cavities within the tumour. Histological examination showed the appearances of a giant-cell tumour of Grade II (Figs. 10 and 11).

After operation the spine was immobilised in a plaster jacket. The neurological disturbances disappeared within a month. Radiographs after operation showed diminution of the gap between the first and third lumbar vertebral bodies with some anterior angulation of the spine and with posterior displacement of the body of the first lumbar vertebra (Fig. 12).

In order to avoid further angulation it was decided to bridge the gap by bone grafting. At operation in November 1958 the spine was approached through a left antero-lateral retroperitoneal route, with the patient in a position of marked extension of the lumbar spine. No recurrence of the tumour was found, and the space between the vertebral bodies was filled by what appeared to be fibrous tissue; this was confirmed by histological examination. Two tibial cortical grafts were taken and prepared so that they were as long as the vertebral bodies were broad and as broad as the space between the first and third lumbar vertebral bodies. They were put in the front and the back of the space between the bodies and were firmly grasped in this situation. The space between them was filled up by chips of cancellous bone. Posterior fusion was added at the same time. The patient was kept in plaster which was retained for six months after operation. At that time radiographs showed satisfactory fusion.

In May 1964, almost six years after the second operation, the patient was found to have married and to have had a child. She had no complaints and there were no neurological signs or symptoms. Radiographs showed that the grafts between the first and third lumbar vertebral bodies had fused very well (Figs. 13 and 14). There was slight anterior angulation of the upper lumbar spine.

Case 5-A man of twenty-two began in May 1956 to get stiffness in the neck and pain radiating to the ulnar side of the left upper limb. Four months later the pain started affecting the right upper limb as well. At the time of admission in January 1957 there was marked restriction of movement of the cervical spine. There was wasting of the intrinsic muscles of both hands and diminution of power of the left triceps and pectoralis major. Radiographs showed collapse of the seventh cervical vertebral body with involvement of its left lateral and articular processes (Figs. 15 and 16). There was also posterior subluxation and anterior angulation of the sixth cervical vertebral body. Lumbar puncture showed a delayed response to Queckenstedt's test. The cerebro-spinal fluid appeared yellow and contained 206 milligrams of protein per 100 millilitres.

At operation in January 1957 a left antero-lateral approach was made. The left part of the body of the seventh cervical vertebra was found to be occupied by a bulging tumour mass. This tumour extended into the peridural space. The tumour was cleaned out from the vertebral body and its peridural extension was removed by a posterior approach. Histological examination showed a giantcell tumour of Grade II (Fig. 24). With the posterior approach it was found that the left lamina of the seventh cervical vertebra had been eroded by a greenish brown tumour and that the peridural part of the tumour extended from the sixth cervical to the first thoracic vertebra. After much of it had been removed it was found to have penetrated between the posterior longitudinal ligament and the posterior aspect of the first thoracic vertebral body. Histological examination of this part of the tumour showed the same appearances as those of the anterior part. After operation the patient

VOL. 47 B, NO. 4, NOVEMBER 1965 


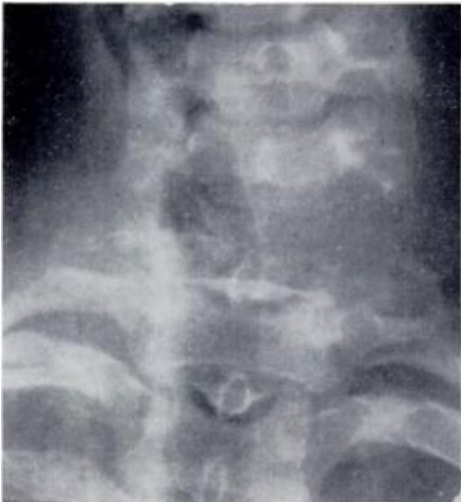

Fig. 15

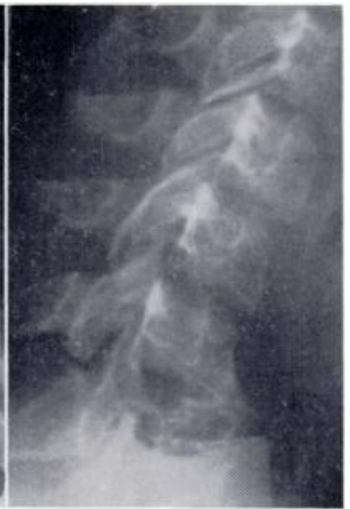

Fig. 16

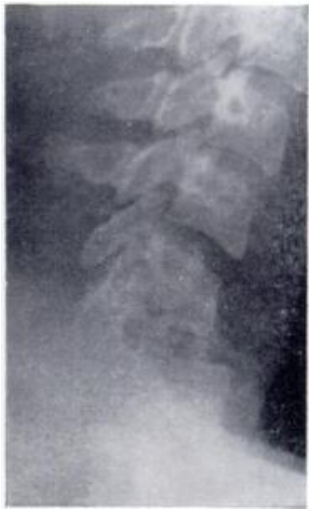

FIG. 17

Case 5-Figures 15 and 16-In January 1957. Figure 15-Invasion of left articular and lateral process of seventh cervical vertebra. Figure 16-Collapse of seventh cervical vertebral body. Figure 17-After operation. Note the removal of the sixth and seventh cervical spinous processes.



FIG. 18

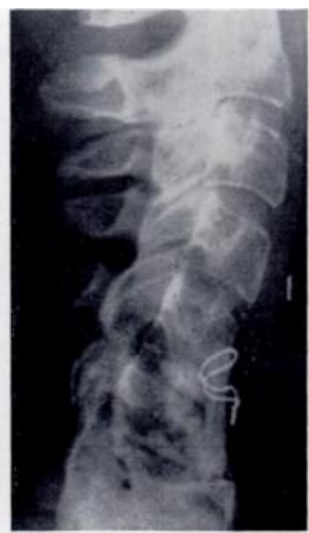

Fig. 19

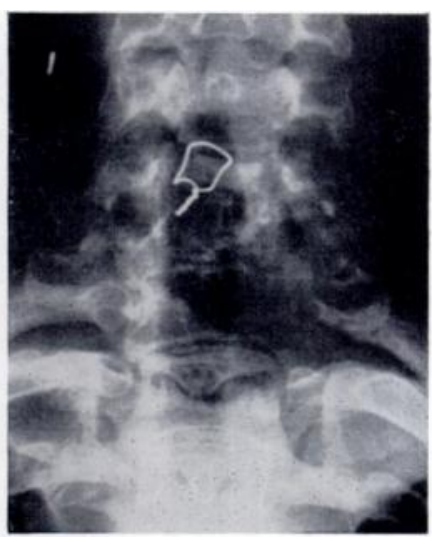

Fig. 20

Case 5-Figure 18-Three and a half years after operation there is forward dislocation of the fifth cervical vertebra. Figure 19-Three months after reduction by traction and stabilisation by insertion of intercorporeal and anterior tibial cortical bone grafts. Figure 20-Five months later there is osteolysis in the middle and left part of the first thoracic vertebral body and of its left lateral process.

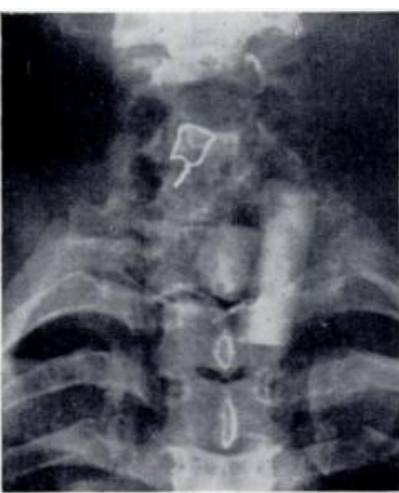

Fig. 21

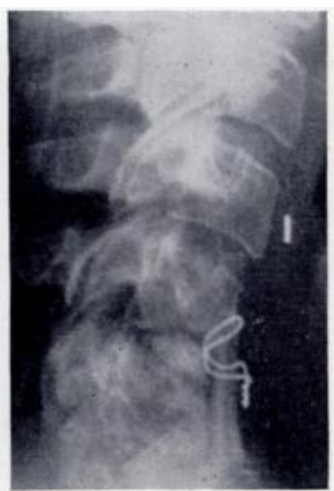

Fig. 22

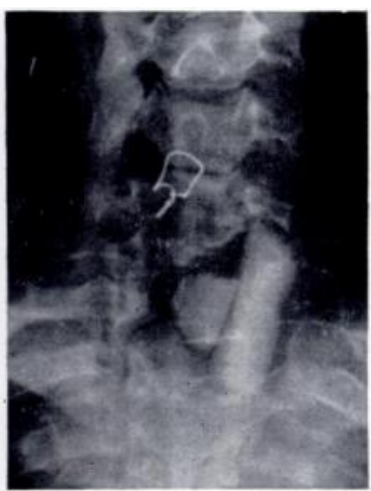

FIG. 23

Case 5-Figures 21 and 22-After removal of tumour mass and insertion of tibial cortical inlay grafts. Figure 23-Two months after the third operation there is progression of osteolysis around the grafts, although these are not involved by tumour. Displacement of the trachea to the right. 


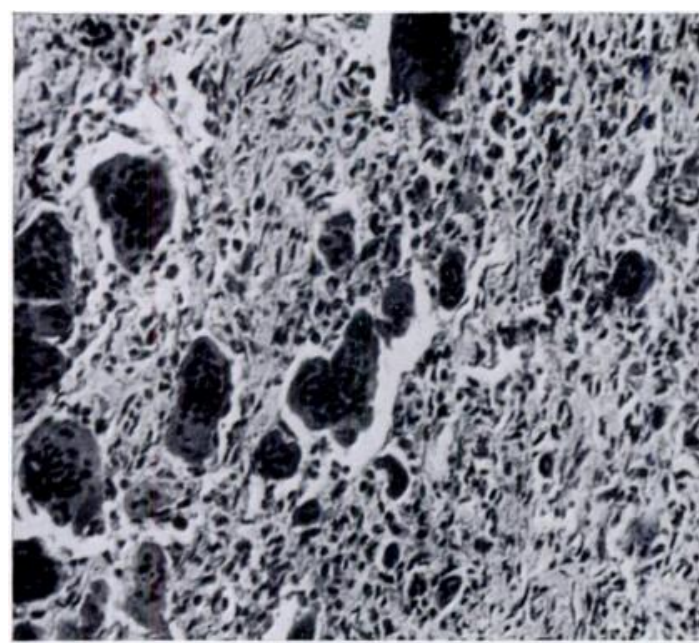

FIG. 24

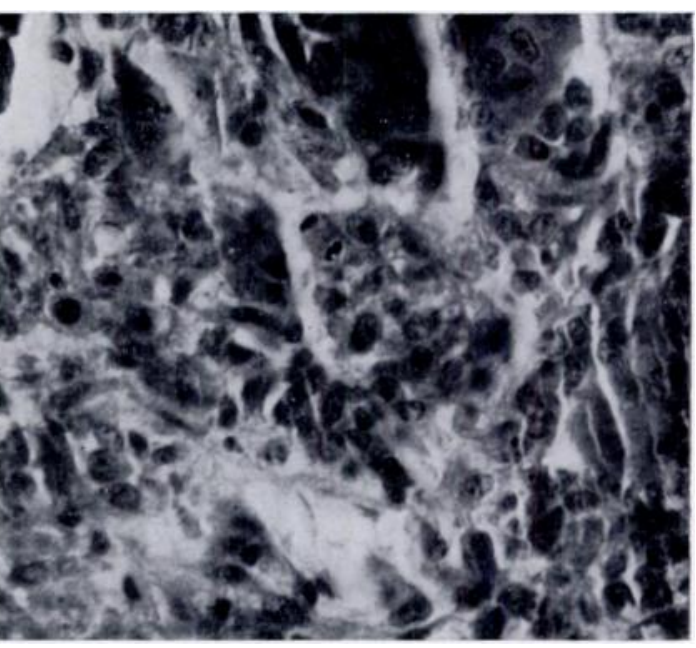

FIG. 25

Case 5-Histological appearances. Figure 24-At time of first operation (1957). Numerous giant cells with many nuclei. No mitotic figures. ( $\times 160$.) Figure 25-Four years later at the time of the fourth operation. Abundant and irregularly arranged stromal cells, many of them with large and hyperchromatic nuclei. Many mitotic figures: one is seen in the centre of the field. $(\times 270$.

received radiotherapy, a total dose of 4,600 röntgens being given. The radiographic appearance after operation is shown in Figure 17.

In September 1960 the patient complained of fatigue and of pain in the neck, though there were no new neurological disturbances. Anterior angulation of the neck had developed, and radiographs showed that this had been caused by forward dislocation of the fifth cervical vertebral body (Fig. 18). There was no radiological evidence of recurrence of the tumour. It was decided to reduce the deformity and to stabilise the spine.

At operation in September 1960 skull traction was applied and the spine was approached by the right antero-lateral route. There was no evidence of recurrence of the tumour in the anterior part of the cervical spine. The disc between the fifth and sixth cervical vertebrae was removed and was replaced by a tibial cortical graft. The deformed anterior part of the sixth cervical vertebral body was removed and replaced by a tibial cortical graft fixed by a wire suture to the antero-inferior margin of the fifth cervical vertebral body (Fig. 19). The patient's neck was immobilised until November 1960.

The patient remained well until April 1961 when he developed pain in and loss of power of the left hand. There was diminution of sensibility in the left eighth cervical dermatome. Radiographs at the time showed marked destruction of the left and middle parts of the first thoracic vertebral body, with destruction also of its left transverse process and of the adjacent part of the first rib (Fig. 20). There was no displacement of the trachea.

A third operation was done in April 1961. A left antero-lateral approach was made, the incision extending to the left from the region of the fourth tracheal ring, with the patient's neck extended. A tumour mass was found in the first thoracic vertebral body and the left eighth cervical nerve was surrounded by tumour. The tumour extended also into the left transverse process and the left upper part of the second thoracic vertebral body. It was carefully removed, together with the parts of it that adhered to the anterior aspect of the dural sac. It was so firmly attached to the eighth cervical nerve that this had to be removed. The same had to be done to the left vertebral artery. In order to stabilise the spine two tibial cortical grafts were put into the defect in the first and second thoracic vertebral bodies. One graft was fixed by a wire suture to the second thoracic vertebra, while its upper end supported the left transverse process of the sixth cervical vertebra. The second graft was put into the space between the lateral graft and the remaining part of the first thoracic vertebral body (Figs. 21 and 22). Histological examination again showed the appearances of a giant-cell tumour showing no signs of malignancy. After operation the patient was relieved of pain, but two months later he developed a paralysis of the left lower limb. Radiographs showed destruction of bone around the grafts and displacement of the trachea to the right (Fig. 23). A tumour mass could be felt in the neck.

A fourth operation was done in July 1961: a prevertebral tumour mass was found but the graft appeared firmly fused. Histological examination this time showed the appearance of a malignant tumour (Fig. 25). The patient died at home in October 1961.

VOL. 47 B, NO. 4, NOVEMBER 1965 
ANEURYSMAL BONE CYSTS INVOLVING VERTEBRAL BODIES

Case 6-A lad of fifteen had suffered from pains in the nape of the neck radiating between the scapulae since an injury to his neck in 1955 . In 1957 he fell from a height of just over twenty feet and in the same year had a motor-cycle accident. He gradually developed a cervico-thoracic scoliosis. An orthopaedic surgeon saw him and made a diagnosis of forward dislocation of the seventh cervical vertebra. Skull traction was applied but within twenty-four hours weakness of the right leg with a positive Babinski sign developed. The following day the left lower limb also was weak. The patient was admitted in January 1958 with a spastic paraplegia and loss of sensibility below the second thoracic level.

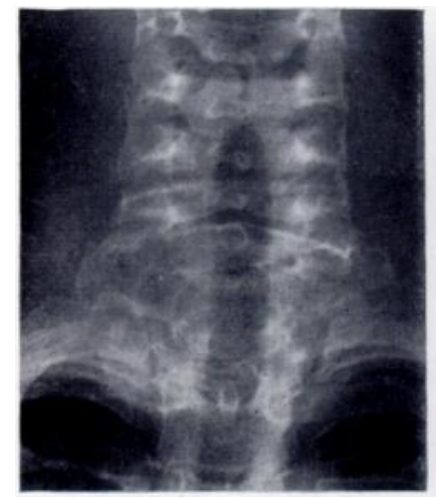

Fig. 26

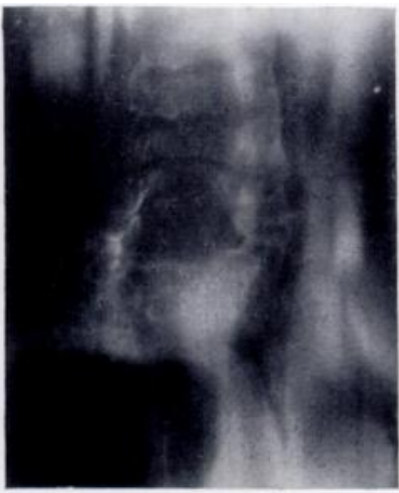

Fig. 27

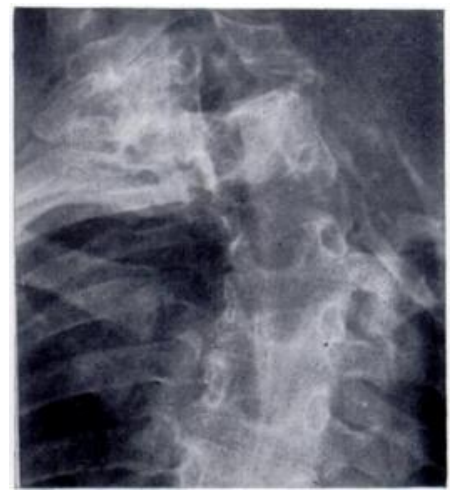

FIG. 28

Case 6-Radiographic appearances. Figure 26-Antero-posterior view shows partial destruction of first and second thoracic vertebral bodies. Figure 27-Tomograph shows clearly the ballooning of the first and second thoracic laminae. Figure 28-A year after operation there is localised kyphoscoliosis.

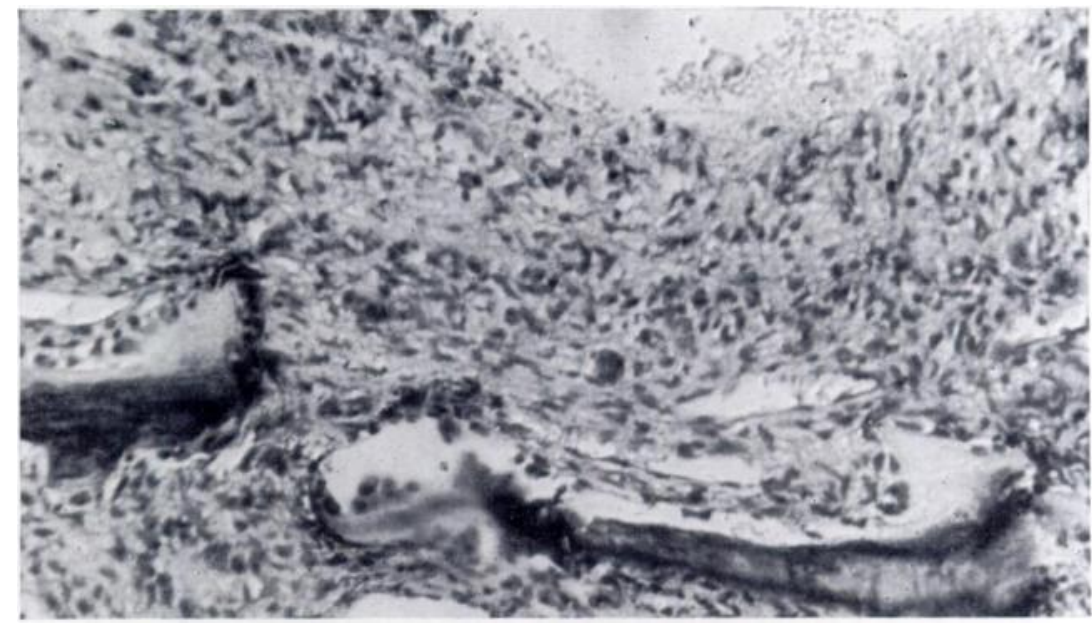

Fig. 29

Case 6-Histological appearances. The wall of the cyst contains connective tissue, sparse small multinuclear giant cells and strands of osteoid tissue. The vascular spaces are lined only by endothelial cells. $(\therefore 180$.)

Radiographs taken at this time showed destruction of the first and second thoracic vertebral bodies and a localised kyphosis. The right transverse process of the first thoracic vertebra had a trabeculated appearance. Tomographs showed that the first and second thoracic laminae were thin and ballooned (Figs. 26 and 27). At operation in January 1958 a left postero-lateral approach was made. The posterior parts of the upper three ribs excluding their articulating medial ends were removed and after separation of the parietal pleura the upper three thoracic transverse processes were removed together with the articulating ends of the ribs. The pedicles of the upper two thoracic vertebrae were exposed and removed together with a part of the left laminae, including the articular processes joining the first and second thoracic vertebrae and the superior articular processes of the first thoracic vertebra. 
An extradural cyst was opened completely surrounding the dural sac and containing brownish viscous fluid. There was a large space between the dural sac and the laminae, and the latter were expanded by the cyst. The posterior part of the first thoracic vertebral body had completely disappeared. The walls of this cyst were carefully removed. The seventh cervical vertebral body was found to be dislocated forwards and to touch with its lower surface the anterior superior margin of the second thoracic body. The posterior superior margin of the second thoracic vertebral body protruded into the angulated spinal canal compressing the dural sac. This part of the vertebral body was removed and the anterior aspect of the vertebral canal was smoothed down so as to give a perfect decompression of the dural sac.

Histological examination showed appearances typical of aneurysmal bone cyst (Fig. 29).

After operation the spine was immobilised in plaster; signs of recovery from the neurological disturbance first appeared two weeks after operation and recovery was complete by the middle of February 1958. The plaster was removed in November 1958. During the following year there was increase of kyphoscoliosis with convexity towards the left (Fig. 28). In April 1964, six years after operation, there was no further increase in the degree of kyphoscoliosis, the patient had no complaints and showed no evidence of neurological disturbance.

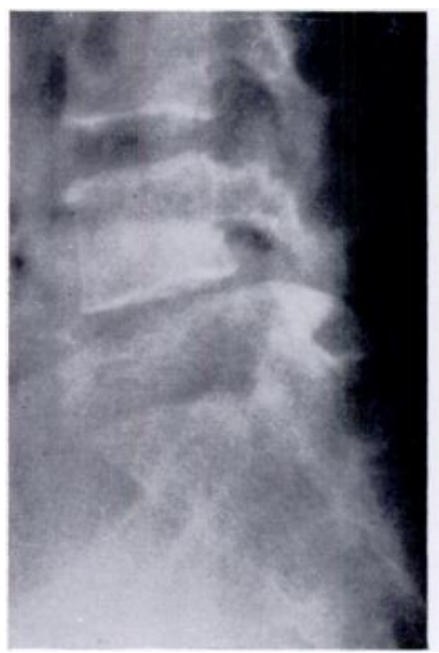

FIG. 30

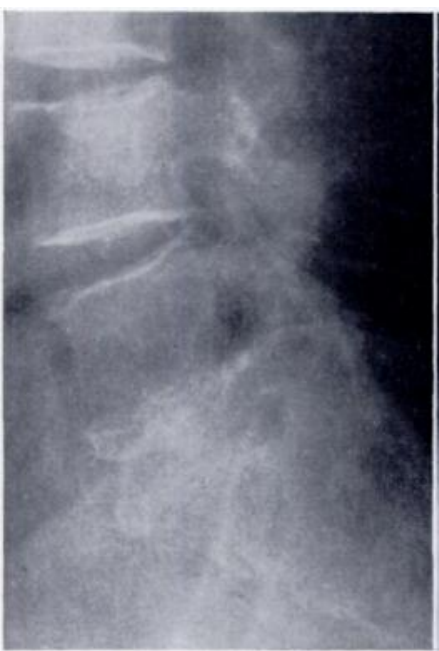

FIG. 31

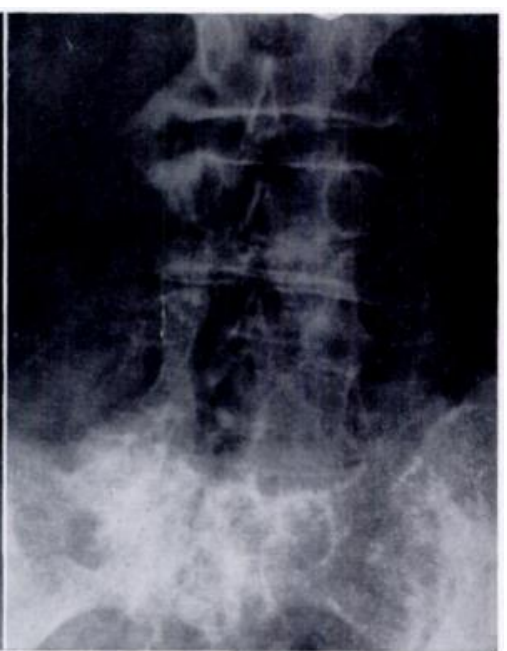

FIG. 32

Case 7-Radiographic appearances. Figure 30-Eefore operation. Destruction of fifth lumbar vertebral body. Figures 31 and 32 - Twenty-one years after operation. The space between the fourth lumbar vertebral body and the sacrum has been almost completely taken up.

Case 7-This patient's case was previously described (Verbiest 1947) and at the time the condition was classified as a giant-cell tumour. A woman of thirty-five sustained an injury to her back in 1937 and after that suffered from low back pain. In 1939 she fell downstairs and after the second accident her symptoms increased. In 1941 radiation of pain to the left lower limb began. She was admitted to a local hospital where a diagnosis of a tumour of the fifth lumbar vertebral body was made. Radiotherapy was given and was followed by increase of the lower limb pain.

On admission in November 1942 the patient could neither stand, sit nor turn in bed because of pain. She kept her left lower limb semi-flexed. There was pain on local pressure in the lumbar area with radiation to the back of the left lower limb. The only objective neurological signs were the diminution of the patellar and ankle reflexes in the right lower limb. Radiographs showed destruction of the fifth lumbar vertebral body with a "blow-out" appearance of the left transverse process. The left lamina of the fifth lumbar vertebra was eroded (Fig. 30). At operation in December 1942 a posterior approach was made. The radiotherapy had caused pronounced changes in the skin and muscle. The tumour had eroded the left lamina of the fifth lumbar vertebra and a reddish green tumour mass was found on the left side of the dural sac. It had invaded also the left transverse process. These parts of the tumour were removed and both fifth lumbar nerves were divided in order to give better access to the vertebral body. Thus the whole fifth lumbar vertebral body, which was completely invaded by the tumour, could be removed. There were no cysts within the tumour. Posterior fusion was done.

The pathological specimen was lost during the destruction of part of the clinic in an air raid. At the time Professor Nieuwenhuyse reported on the tumour as follows: " abundance of giant cells,

VOL. $47 \mathrm{~B}$, NO. 4 , NOVEMBER 1965 
most of them containing more than fifteen nuclei; presence of many stromal cells, thin-walled blood vessels and large blood-filled cavities. Seams of osteoid tissue in the more fibrous portions of the process. Many macrophages laden with haemosiderin and haemosiderin deposits. Although the patient's age is uncommon in the group of aneurysmal bone cysts and the giant cells display fewer nuclei in the latter lesion, it is not improbable that on the basis of the other pathological features this case would be classified at present as an aneurysmal bone cyst."

The posterior grafts did not fuse, probably because of changes induced by the radiotherapy, and had to be removed. The patient was kept in bed for a while and later, because of the circumstances of the war, taken home. She returned in December 1945 walking perfectly well and without any complaints.

Radiographs taken in 1945 showed recalcification of the left fifth lumbar transverse process. The body of the fourth lumbar vertebra had approached the sacrum without producing the slightest kyphosis. There was a slight lateral inclination of the fourth lumbar vertebral body towards the left and a calcified mass joined the fourth lumbar vertebral body to the sacrum. Radiographs taken in August 1954 showed complete recalcification of the left fifth lumbar transverse process which had fused with the adjoining sacrum and ilium. There was no evidence of recurrence of the tumour. Radiographs taken in April 1964, more than twenty-one years after operation, showed a normal degree of lumbar lordosis and perfect lumbo-sacral alignment. The lateral inclination of the fourth lumbar vertebra was less pronounced than it was in 1954 (Figs. 31 and 32). There was some degenerative change in the upper two lumbar vertebrae. The patient was in good health and had no complaints. There was, in fact, no clinical or radiological evidence of recurrence.

\section{COMMENT}

Giant-cell tumours-Only one of the five patients was under twenty, three were in the third decade of life and one was forty-one. Radiological examination showed rarefaction of bone in three cases and in one case a lumbar vertebral body presented a blow-out appearance, the bulging tumour mass being surrounded by a thin shell of cortex. In the case of malignant giant-cell tumour of the posterior wall of the sacral canal there were no radiological abnormalities. In all cases the tumour had penetrated the bone and surrounded the dural sac, invading intervertebral foramina (Case 1), the neck muscles (Case 2) and the psoas muscle (Case 4); extending along the posterior surface of the sacrum (Case 3) or passing between the posterior longitudinal ligament and the posterior aspect of the vertebral bodies (Case 5). In no case was there cyst formation; in each, histological examination showed the characteristic features of giant-cell tumours of bone, and even the cavernous vascular spaces seen in aneurysmal bone cysts were absent.

An $x$-ray dosage of 1,800 röntgens produced sudden paraplegia and radicular pains in Case 4 and increasing lumbago and radicular pains in Case 7. Exacerbation of the lesion after initiation of $\mathrm{x}$-ray therapy is a well known phenomenon, which has been described as paradoxical reaction (Herendeen 1924) or pseudomalignant behaviour (Trifaud, Bureau and Payan 1959). Whereas these reactions are of minor clinical importance in giant-cell tumours of the long bones, they are less innocuous when they occur in vertebral tumours. Primary moderate irradiation of vertebral giant-cell tumours is not devoid of risk.

Results-Three patients are alive and free from symptoms ten, six and six years after complete removal of the lesion. Two patients died. In Case 3 the tumour, localised in the sacrum, was malignant from the beginning. In Mnaymneh, Dudley and Mnaymneh's series the sacral giant-cell tumours had a higher incidence of malignant transformation than those in other locations.

The malignant transformation in Case 5 raises the question whether this should be considered a result of previous irradiation.

At present there is general agreement that high doses $(4,000$ röntgens or more) should be avoided because of the danger of inducing sarcomatous change in the bone, well known since Hatcher's (1945) and Cahan, Woodard, Higinbotham, Stewart and Coley's (1948) publications; and also because of the reduction of the regenerative capacity of the involved bone, a fact deserving special attention in cases of giant-cell tumours involving a vertebral body. The 
possibility of malignant transformation of a giant-cell tumour under the influence of $x$-ray treatment is still an open question, because malignant evolution may occur spontaneously. On the other hand, there is no consensus of opinion about the effectiveness of x-ray treatment in these lesions. Papers by Prossor (1949), Windeyer and Woodyatt (1949) and Ellis (1949) stressed the superiority of radiation to treatment by surgical measures. Johnson and Dahlin (1959), reporting 116 cases from the Mayo Clinic, stated that radiation therapy alone was not successful in controlling any of the tumours, and recently Mnaymneh, Dudley and Mnaymneh (1964) in an analysis of forty-one cases observed at the Massachusetts General Hospital found the results of radiation alone or combined with curettage or partial excision remarkably inferior to those of total excision.

Aneurysmal bone cysts-The age of the patient in Case 6 is in accordance with the tendency of these lesions to occur in young people. The cyst was empty except for viscous brown fluid. The wall displayed the typical features of an aneurysmal bone cyst. The tumour surrounded the spinal canal and involved the laminae, articular processes and bodies of the upper two thoracic vertebrae. The diagnosis in Case 7 is questionable since the specimen was lost and could not be re-examined. The patient's age and the great number of nuclei within the giant cells are unusual in aneurysmal bone cyst, though the other pathological features would allow its classification as one. In this case the tumour had also penetrated the bony cortex and invaded the spinal canal. Although there remains some doubt as to the exact diagnosis, this case has been included in this series because of absence of recurrence after twenty-one years and the surgical problems entailed in the removal of the fifth lumbar vertebral body.

\section{PROBLEMS OF SURGERY OF THE VERTEBRAL BODIES}

Surgical treatment of vertebral tumours aims at 1) complete removal of the tumour; 2) decompression and protection of the spinal cord, including reduction of vertebral dislocation; and 3) stabilisation of the vertebral column. Special problems arise when removal of the tumour entails the extirpation of the major portion of one or more vertebral bodies or their complete excision. There is no doubt that the ideal treatment consists of replacing those bodies, either by using bone grafts alone or combining them with the insertion of a prosthesis, as has been done in Krayenbuhl's clinic by Senning, Weber and Yasargil (1962). When bone grafts alone are used some time is required for fusion so that their value is limited in rapidly growing tumours, but in more favourable cases they provide the most adequate means of stabilisation of the spinal column. The technique of grafting depends on the area involved, and special measures are required for fixation in cases of involvement of the very mobile cervical spine. In a previous paper the author demonstrated that replacement of the lower vertebral bodies in the case of injury can be satisfactorily achieved by combining tibial cortical inlay and iliac onlay grafts. This technique was not yet developed when operation was done in Cases 5 and 6. In the former case removal of the seventh cervical body by curetting was followed three years later by anterior angulation caused by forward displacement of the fifth cervical body. This was promptly reduced by traction and reduction was made secure by combined anterior and intercorporeal fusion of the fifth and sixth cervical vertebrae.

In a later phase in the same case it was shown that the first and second thoracic vertebral bodies could be replaced by tibial cortical inlay grafts alone. This procedure could be carried out without difficulty through an anterior approach at the level of the fourth tracheal ring, which even allowed wiring of the graft to the remaining portion of the second thoracic vertebral body. The resistance of these grafts to the tumour, which destroyed the surrounding bone, was remarkable.

In Case 6 a postero-lateral approach was necessary because the lesion extended in both the anterior and posterior segments of the involved vertebrae, but the operation contributed to the instability of the spine, and resulted in increasing anterior angulation. In retrospect 
it can be seen that an additional, transthoracic, operation would have permitted mobilisation and reduction of the dislocated seventh cervical body, and that stabilisation could have been obtained by anterior fusion.

As to the cases of lumbar involvement, removal of the fifth lumbar vertebral body resulted in spontaneous fusion between the bodies of the fourth lumbar vertebra and of the first sacral segment by a calcified mass. Alignment of the spine was perfect and the patient was in excellent condition twenty-one years later.

On the other hand, removal of the second lumbar vertebral body in Case 4 was followed by progressive diminution of the gap, accompanied by increasing anterior angulation of the spine. For this reason the gap was bridged by tibial cortical inlay grafts, and posterior fusion was done at the same time. During a follow-up of six years the patient did perfectly well.

The approach to the vertebral bodies varies with the various levels but is nowadays well standardised. It is seldom necessary to remove a vertebral body for neoplastic involvement and the problem of replacement varies not only with the level involved but also with the extent of destruction. More reports in this field with observations covering many years are greatly needed.

\section{SUMMARY}

1. Five cases of involvement of vertebrae by growths classified as giant-cell tumours, and two cases of involvement by tumours classified as aneurysmal bone cysts are described.

2. The periods of observation after operation in the benign cases were in three cases six years, in one ten years and in one twenty-one years.

3. In one case malignant transformation developed four and a half years after operation and one patient, in whom a sacral tumour was already malignant at the time of operation, died five months later.

4. Four patients showed significant involvement of vertebral bodies.

5. The problems related to the removal of a vertebral body and the measures taken to stabilise the spine are discussed.

I am greatly indebted to the pathologist, Professor T. Vossenaar, for his advice and aid in preparing the photomicrographs.

\section{REFERENCES}

BLoodgood, J. C. (1919): Bone Tumors. Central (Medullary) Giant-Cell Tumor (Sarcoma) of Lower End of Ulna, with Evidence that Complete Destruction of the Bony Shell or Perforation of the Bony Shell is not a Sign of Increased Malignancy. Annals of Surgery, 69, 345.

BucY, P. C. (1962): Some Primary (Malignant?) Tumors of the Spine. Clinical Neurosurgery, 8, 32.

Cahan, W. G., Woodard, H. Q., Higinbotham, N. L., Stewart, F. W., and Coley, B. L. (1948): Sarcoma Arising in Irradiated Bone. Cancer, 1, 3.

Cooper, A., and Travers, B. (1818): Surgical Essays. Philadelphia: James Webster.

Donaldson, W. F., Jun. (1962): Aneurysmal Bone Cyst. Journal of Bone and Joint Surgery, 44-A, 25.

Ellis, F. (1949): Treatment of Osteoclastoma by Radiation. Journal of Bone and Joint Surgery, 31-B, 268.

Hatcher, C. H. (1945): The Development of Sarcoma in Bone Subjected to Roentgen or Radium Irradiation. Journal of Bone and Joint Surgery, 27, 179.

Herendeen, R. E. (1924): The Roentgen Ray in the Treatment of Giant-cell Tumors. American Journal of Roentgenology and Radium Therapy, 12, 117.

Hess, W. E. (1960): Giant-Cell Tumor of the Cervical Spine. Journal of Bone and Joint Surgery, 42-A, 480.

JAFFe, H. L. (1958): Tumors and Tumorous Conditions of the Bones and Joints. Philadelphia: Lea and Febiger.

JAffe, H. L., Lichtenstein, L., and Portis, R. B. (1940): Giant-Cell Tumor of Bone. Its Pathologic Appearance, Grading, Supposed Variants and Treatment. Archives of Pathology, 30, 993.

Johnson, E. W., Jun., and Dahlin, D. C. (1959): Treatment of Giant-Cell Tumor of Bone. Journal of Bone and Joint Surgery, 41-A, 895.

Lichtenstein, L. (1959): Bone Tumors. St Louis: The C. V. Mosby Company.

McCarty, C. S., Dahlin, D., Doyle, J. B., Lipscomb, P. R., and Pugh, D. G. (1961): Aneurysmal Bone Cysts of the Neural Axis. Journal of Neurosurgery, 18, 671. 
Mnaymneh, W. A., Dudley, H. R., and Mnaymneh, L. G. (1964): Giant-Cell Tumor of Bone. Journal of Bone and Joint Surgery, 46-A, 63.

Nélaton, E. (1860): D'une nouvelle espèce de tumeurs bénignes des os, ou tumeurs à myéloplaxes. Paris: A. Delahaye.

Paillas, J. E., Serratrice, G., and Legré, J. (1963): Les Tumeurs Primitives du Rachis. Paris: Masson et Cie. Prossor, T. M. (1949): Treatment of Giant-cell Tumours of Bone. Journal of Bone and Joint Surgery, 31-B, 241. Schajowicz, F. (1961): Giant-Cell Tumors of Bone (Osteoclastoma). Journal of Bone and Joint Surgery, 43-A, 1.

Senning, A., Weber, G., and Yasargil, M. G. (1962): Zur operativen Behandlung von Tumoren der Wirbelsaüle. Schweizerische Medizinische Wochenschrift, 92, 1574.

Stewart, M. J. (1922): The Histogenesis of Myeloid Sarcoma. Lancet, ii, 1106.

Trifaud, A., Bureau, H., and Payan, H. (1959): Tumeurs bénignes des Os. Paris: Masson et Cie.

Verbifst, H. (1947): Le traitement neurochirurgical dans les tumeurs bénignes des corps vertébraux avec compression de la moelle. Reviue Neurologique, 79, 528.

Verriest, H. (1962a): Anterior Operative Approach in Cases of Spinal Cord Compression by Old Irreducible Displacement of Fresh Fracture of Cervical Spine. Journal of Neurosurgery, 19, 389.

Verbiest, H. (1962b): Trois types d'opération antérieure dans certaines luxations et fracture-luxations du rachis cervical. Neurochirurgie, 8, 253.

Williams, R. R., Dah! in, D. C., and Ghormi.ey, R. K. (1954): Giant-Cell Tumor of Bone. Cancer, 7, 764.

Windeyer, B. W., and Woodyatt, P. B. (1949): Osteoclastoma. Journal of Bone and Joint Surgery, 31-B, 252.

VOL. 47 B, NO. 4, NOVEMBER 1965 